\title{
Sexual Practices and Perceived Susceptibility to HIV Infection among Men : ho have Sex with Men in Dar Es Salaam, Mainland Tanzania
}

\section{Elia J. Mmbaga ${ }^{1 *}$, Mbulla J. Dodo², Germana H. Leyna1, Kare Moen ${ }^{3}$ and Melkizedeck T. Leshabari²}

${ }^{1}$ Department of Epidemiology and Biostatistics, Muhimbili University of Health and Allied Sciences, Dar Es Salaam, Tanzania ${ }^{2}$ Department of Behavioral Sciences, Muhimbili University of Health and Allied Sciences, Dar Es Salaam, Tanzania

${ }^{3}$ Institute of Health and Society, University of Oslo, Oslo, Norway

\begin{abstract}
This paper is the first in mainland Tanzania to report on sexual practices and HIV perceived risk of Men who have Sex with Men (MSM). A total of 150 MSM with a mean age of 21.3 were recruited using a respondent-driven sampling. Their median age at first anal sex was 12.2 and their median number of lifetime sexual partners was 35. The majority $(94.0 \%)$ of the respondents reported more than two sex partners in the three months preceding the survey, and $32.0 \%$ reported involvement in heterosexual relationships. Two-thirds of the participants had low HIV perceived risk, which was associated with involvement in heterosexual relationships (AOR, 3.6, 95\% $\mathrm{Cl}$ : 1.015.0), lower condom use (AOR, 0.3, 95\% Cl: 0.2-0.7), alcohol consumption (AOR, 6.0, 95\% Cl: 2.3-16.9) and lower likelihood of ever having been tested for HIV (AOR, 0.3, 95\% CI: 0.1-0.9). Focuses in HIV prevention have excluded MSM and our results indicate the need to consider this group in HIV programming in Tanzania.
\end{abstract}

Keywords: HIV; Perceived risk; Sexual practices; Men having sex with men, Tanzania

\section{Introduction}

The HIV/AIDS epidemic has been a threat to public health and development in Sub-Saharan Africa. Other things being equal, unprotected anal sex with one infected partner carries a higher risk of HIV infection than other types of sexual practices. Studies on HIV prevalence among Men who have Sex with Men (MSM) conducted in various African countries have revealed prevalence rates which are higher (2-20 times) than that of the general population [1-4]. Yet, HIV-related research and programming in many parts of Africa and elsewhere have often failed to address anal sex in general and male-tomale penile-anal sex in particular.

Some studies have demonstrated that MSM may often conceal their homosexual identities from their families and the general population and avoid seeking health care due to fear of potential negative consequences [5-7]. Homosexuality is highly stigmatized in some strata of society, and sex between men constitutes a crime in 31 African countries including Tanzania [7-11]

The likelihood of multiple sexual partnerships among MSM is high compared to that of the general population. MSM are reported to have a wide range of relationships among themselves and with women in the general population [12-14]. This link between MSM and women in the general population plays an important role in facilitating transmission between this high infection rate group and the general population [14].

So far there are few studies on MSM in Tanzania and to our knowledge no epidemiological studies on MSM from mainland Tanzania. A recent survey in Zanzibar found that the HIV prevalence was considerably higher among MSM (12.3\%) than among the general population $(0.8 \%)[4,15]$. It is not yet known how this compares with the situation in Dar Es Salaam, is not yet known, but the close proximity of the two sites makes it likely that similar rates apply in this main urban center of Tanzania. To mount a comprehensive response to the HIV epidemic, it is imperative that all population subgroups at risk be included in prevention programming. This study aims to contribute to this goal by offering insight into the characteristics of MSM, their selfperceived susceptibility to HIV infection, and their sexual practices.

\section{Methods}

\section{Study area}

This study was conducted in Dar Es Salaam, Tanzania's largest city with a population of about four million. Dar Es Salaam is also one of Tanzania's 26 administrative regions, and the second highest ranking of these in terms of HIV prevalence (9.3\% versus the country average of 5.7\%). Compared with other regions of the country, Dar Es Salaam has also been characterized as having a higher percentage of both men and women who engage in unprotected sexual intercourse with multiple sexual partners [16]. The region has a mix of people from other parts of the country as well as foreigners with different cultural backgrounds. The city is divided into three municipalities: Kinondoni, Ilala, and Temeke.

\section{Population and design}

This was a cross-sectional study among men from 15 to 49 years of age who have occasional or regular sex with other men and who reside in Dar Es Salaam. 'Residence' was taken to mean that the person currently had an address in the city and had been living in Dar Es Salaam for at least 6 months. The study was conducted between May and June 2011.

\section{Sampling technique}

A Respondent Driven Sampling method (RDS) was used in the recruitment of study participants. RDS is a referral-based system in

*Corresponding author: Dr. Elia John Mmbaga, Department of Epidemiology and Biostatistics, Muhimbili University of Health and Allied Sciences, P.O.Box 65015, Dar es Salaam, Tanzania, Tel: +255714213524; E-mail: eliajelia@yahoo.co.uk

Received April 08, 2012; Accepted June 15, 2012; Published June 19, 2012

Citation: Mmbaga EJ, Dodo MJ, Leyna GH, Moen K, Leshabari MT (2012) Sexual Practices and Perceived Susceptibility to HIV Infection among Men who have Sex with Men in Dar Es Salaam, Mainland Tanzania. J AIDS Clinic Res S1:012. doi:10.4172/2155-6113.S1-012

Copyright: (c) 2012 Mmbaga EJ, et al. This is an open-access article distributed under the terms of the Creative Commons Attribution License, which permits unrestricted use, distribution, and reproduction in any medium, provided the original author and source are credited. 
which participants refer a limited number of friends or acquaintances who are also member of the target population to participate in the study.

The recruitment process begins with recruitment of a small number of non-randomly selected persons ("seeds") belonging to the population of interest. Seeds are asked to identify a small number of network members who are then approached and asked to participate. The newly recruited members are in turn asked to approach some of their acquaintances with the same request. Each generation of participants recruited in this fashion is called a 'wave' [17].

RDS is a snowball-sampling technique but it has been improved to overcome the weaknesses of other snowballing techniques. It provides the theoretical basis to produce population estimates through statistical adjustment. The underlying assumption of RDS is that the long chain of recruitment can be modeled, allowing for the calculation of sample weights and standard error that adjust for other biased recruitment patterns. In order to prevent oversampling from large personal networks, RDS limits the number of individuals that may be contributed by a single recruiter thus allowing for an increase in social distance between the seeds, recruiters and later waves $[18,19]$.

\section{Sampling}

In this study, the respondent driven sampling consisted of two distinct phases. Firstly, the initial sample (seeds, or wave zero) was identified among the members of the target population through the researcher's contacts. The seeds were primarily obtained from our previous qualitative study in the area, which indicated that the population was not very difficult to reach [20]. Three seeds were identified from the city and given three invitation cards each to pass to other network members in their population sub-group. To be able to estimate network size, each seed was given a different color of invitation cards and all subsequent recruits were asked about their knowledge and connection with the recruiter. The rest of the sample was selected by following the links from previous respondents, creating an expanding system of referral chains and yielding 150 respondents for a two-week period of data collection.

\section{Interviews}

The interviews conducted for this study followed a structured questionnaire and were conducted in face-to-face encounters with the study participants. Issues covered in the interviews included sociodemographic characteristics, sexual behaviors, HIV risk perception and susceptibility, and alcohol and substance use. The data collection instrument was developed based on the results of our preceding qualitative study in which terminology describing local MSM was identified for use in this quantitative study. To further ensure that the questionnaire used terminologies that would be understood by the study population and that it would measure what the study intended to measure (validity), we pretested it among the seeds. Because the seeds were used in the final check of the data collection tool, their data were not included in the final analysis. The interviews were performed in private locations by the researchers themselves to ensure confidentiality. All interviews were conducted in Swahili, the language spoken by all Tanzanians. Participants were given a small stipend as reimbursement for transport to the interview venue.

\section{Ethical consideration}

Ethical approval was obtained from the Research and Publication Committee of Muhimbili University of Health and Allied Sciences. Permission to conduct the study was also obtained from the municipal authorities of Dar Es Salaam. Written informed consent was obtained from all participants before the commencement of the interviews. Study participants were informed that participation was voluntary and that they were free not to answer any question if they so wished at any time during the interview. To ensure confidentiality and cooperation, interviews were conducted in private and secure places chosen by the participants themselves. All participants were offered preventive education regarding condom use, multiple sexual partnerships, and use of water-based lubricants, and referred to a nearby HIV testing center offering free testing for voluntary counseling and testing. Those who reported sexual coercion or sexual activity while under the minimum legal age in Tanzania were referred to a local organization dealing with sexual and child abuse and offered counseling.

\section{Data analysis}

Data were checked daily for consistency and completeness during the entire data collection period. Data were entered using Statistical Program for Social Scientists (SPSS) version 15 and analyzed using STATA version 11.2. Since the selection probability is not the same for each of the participants when RDS is applied, with larger networks more likely to be represented than smaller ones, data were weighted according to network size by calculating weight as an inverse of the participant's network size $[17,19]$. To reduce clustering and ensure that the whole sample is reflected in the analysis, we multiplied the weight by the sample size and divided it by the sum of the weights. To give an overview of the sample characteristics, we present un-weighted sample data in Table 1 of our results, and all statistical tests were weighted to control for clustering. Frequencies of categorical variables were calculated to show their proportional distribution. Mean and standard deviation were used to summarize continuous variables.

Logistic regression models were built to identify independent associations between risk perception and the practice of risk behaviors in this population. All analyses were two-tailed and the significance level was set at $5 \%$.

\begin{tabular}{|l|l|c|c|}
\hline Variable & Category & n & $\%$ \\
\hline Age & $>19$ & 27 & 18.0 \\
\hline & $19-24$ & 90 & 60.0 \\
\hline Education level & $\geq 25$ & 33 & 22.0 \\
\hline & No formal education & 42 & 28.0 \\
\hline & Primary education & 39 & 26.0 \\
\hline Marital status & Secondary and above & 69 & 46.0 \\
\hline & Single & 102 & 68.0 \\
\hline & Married & 18 & 12.0 \\
\hline & Divorced/separated/Widowed & 11 & 7.3 \\
\hline Number of children & Cohabiting with a man & 19 & 12.7 \\
\hline & No children & 108 & 72.0 \\
\hline & 1 child & 23 & 15.3 \\
\hline Religion & $\geq 2$ children & 19 & 12.7 \\
\hline & Muslim & 64 & 42.7 \\
\hline & Roman Catholic & 24 & 16.0 \\
\hline & Other Christian & 62 & 41.3 \\
\hline Occupation & Employed & 24 & 16.0 \\
\hline & Students & 13 & 8.7 \\
\hline & Petty business & 79 & 52.7 \\
\hline & Unemployed & 34 & 22.6 \\
\hline & & & \\
\hline & & & \\
\hline
\end{tabular}

$\infty$ Un-weighted

Table 1: Distribution of Socio-demographic characteristics among MSM in Dar Es Salaam, Mainland Tanzania. 


\section{Results}

During the study period, a total of 150 men who have regular or occasional sex with men were recruited into the study. More than half (54.0\%) were born in Dar Es Salaam, while the rest came from other parts of Tanzania (42.0\%) and from Mombasa, Kenya (4.0\%). The age of the respondents ranged from 15 to 40 years and the mean age was 21.3 (Standard deviation (SD) 2.1 ) years. A large majority $(78.0 \% ; 117)$ of the study population consisted of young people aged 24 years and below. A total of 69 (46.0\%) participants reported having completed secondary education or higher while $42(28.0 \%)$ reported having no formal education.

Two thirds of the participants (102; 68.0\%) were single, 18 (12.0\%) reported being in marital relationships with women, and $19(12.7 \%)$ were cohabiting with men. Although a majority $(108 ; 72.0 \%)$ of participants did not have children, a little more than one-quarter of them reported being fathers; 23 of the participants (15.3\%) had one child while (12.7\%) had two or more children.

At the time of the interview, $54.7 \%$ of the participants were engaged in petty business, $16.0 \%$ had formal employment, $8.7 \%$ were students and $22.6 \%$ characterized themselves as unemployed. More than half of the participants $(57.3 \%)$ were Christian (16\% belonged to the Roman Catholic Church and $41.3 \%$ to other Christian denominations) while $42.7 \%$ were Muslim. The participants' socio-demographic characteristics are summarized in Table 1.

\section{First sexual practice}

The weighted mean age at sexual debut was 12.2 (1.7 SD) years. With regard to the type of first sexual experience, more than three fifths $(60.7 \%)$ of the participants reported anal sex as their first sexual experience, with $32.0 \%$ and $3.3 \%$ reporting vaginal sex and masturbation/oral sex, respectively.

When asked what had worried them most the first time they had sex, nearly two thirds (64\%) reported worry that their parents would find out that they were sexually active. Worries about STIs including HIV transmission were reported by $20.7 \%$ of participants. Condom use during the first sexual experience was reported by $14.7 \%$ of the participants.

The most common venues for first anal sex were at home (23.3\%) or in the home of a partner $(22.0 \%)$, but some debuted in a boarding school (19.3\%).

The interviewed men were asked to choose between four reply options regarding what they perceived to have been their main motivation for engaging in anal sex the first time they did so. A majority (59.3\%) chose 'pleasure' as their answer, whereas one-fifth (20.0\%) indicated having been forced. Very few (1.3\%) had their first anal sexual experience because they were promised and/or offered a gift.

\section{Sexual practices}

A majority of the participants $(83.3 \%)$ had a fixed positioning preference in penile-anal sex; $65.3 \%$ reported mainly preferring the receptive position while $18.0 \%$ preferred the insertive. The remaining $16.6 \%$ indicated that they practice both insertive and receptive penileanal sex. The last time they engaged sexually with another man, $57.3 \%$ of the interviewed men reported to have engaged in receptive, $16.0 \%$ in insertive, and $26.7 \%$ in both insertive and receptive anal sex. The

\begin{tabular}{|c|c|c|}
\hline Variable & Category & Weighted proportions (\%) \\
\hline & & $N=150$ \\
\hline \multirow{3}{*}{ Type of sex } & Insertive & 18.1 \\
\hline & Receptive & 65.3 \\
\hline & Both & 16.6 \\
\hline \multirow[t]{2}{*}{ Age at first sex } & $\leq 12$ years & 54.0 \\
\hline & $>12$ years & 46.0 \\
\hline \multirow[t]{4}{*}{ Reasons for first sex } & Pleasure & 59.3 \\
\hline & Forced & 20.0 \\
\hline & Gift & 13.3 \\
\hline & Others & 7.4 \\
\hline \multirow[t]{2}{*}{ Has female partner } & Yes & 32.7 \\
\hline & No & 67.3 \\
\hline \multicolumn{3}{|l|}{$\ddagger$ No. of female partners } \\
\hline & 1 & 77.6 \\
\hline & $2+$ & 22.4 \\
\hline \multirow[t]{2}{*}{ Sex of last sexual partner } & Male & 92.7 \\
\hline & Female & 7.3 \\
\hline \multirow[t]{3}{*}{ No. partners last 3 months } & 1 & 6.0 \\
\hline & $2-5$ & 62.0 \\
\hline & $>5$ & 32.0 \\
\hline \multirow[t]{3}{*}{ Type of last sex } & Insertive & 16.0 \\
\hline & Receptive & 57.3 \\
\hline & Both & 26.7 \\
\hline \multirow[t]{2}{*}{ Condom use last sex } & Yes & 36.7 \\
\hline & No & 63.3 \\
\hline \multirow[t]{2}{*}{ Ever used alcohol } & Yes & 92.7 \\
\hline & No & 7.3 \\
\hline \multirow[t]{2}{*}{ Used alcohol during last sex } & Yes & 72.0 \\
\hline & No & 28.0 \\
\hline \multirow[t]{2}{*}{ Ever used drugs } & Yes & 37.3 \\
\hline & No & 62.7 \\
\hline \multirow[t]{2}{*}{ \#Used drugs during last sex } & Yes & 32.7 \\
\hline & No & 67.3 \\
\hline
\end{tabular}

\#. Among those reported use of drugs; $\ddagger$-For those reported to have had female sexual partner(s)

Table 2: Weighted frequency distribution of risk practices reported by MSM in Dar Es Salaam , Mainland Tanzania.

median lifetime number of sex partners was 35 (range 10 to 60), and during the three last months before the interview, $94.0 \%$ of the participants reported having had two or more sex partners. Moreover, at the time of the survey, $32.6 \%$ of participants reported having at least one female partner, and $44.8 \%$ of these said they had more than one partner of the opposite sex (Figure 1).

Most of the study participants (92.7\%) had drunk alcohol at some point in their lives, and $72.0 \%$ had used alcohol in connection with their last sexual experience. Use of other illicit drugs such as cocaine and cannabis was reported by $37.3 \%$ of the participants with $32.7 \%$ reporting drug use during their last sexual act (Table 2 and Figure 1).

\section{Perceived susceptibility to HIV infection}

With regard to self-perceived risk for HIV infection, $36.7 \%$ of study participants perceived themselves to be at higher risk of HIV infection (Figure 2). About half (53.4\%) of the study participants reported having ever been tested for HIV and the majority (78.7\%) were tested more than 4 years preceding the survey. At their last sexual encounter, $36.7 \%$ of the surveyed men said they had used a condom and $42.0 \%$ reported that they had used a lubricant (Figure 1). 


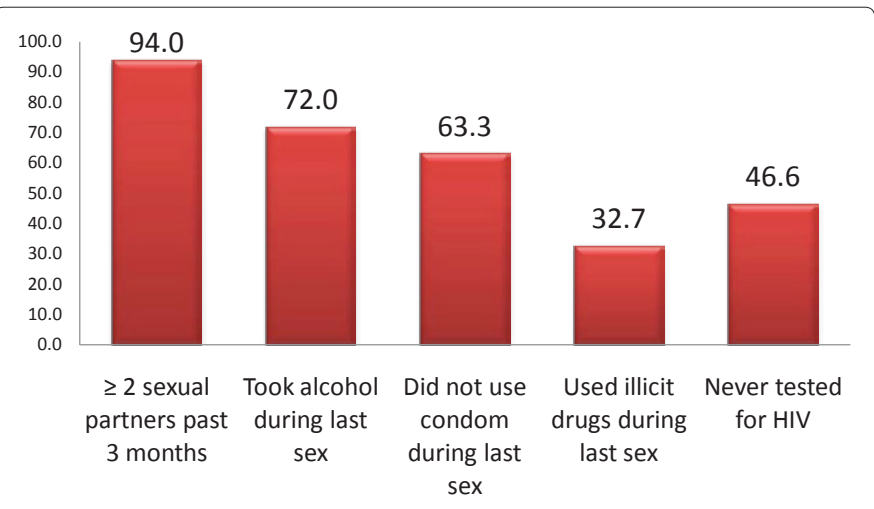

Figure 1: Weighted distributions of risk behaviors practices by MSM in Dar Es Salaam city, Mainland Tanzania.

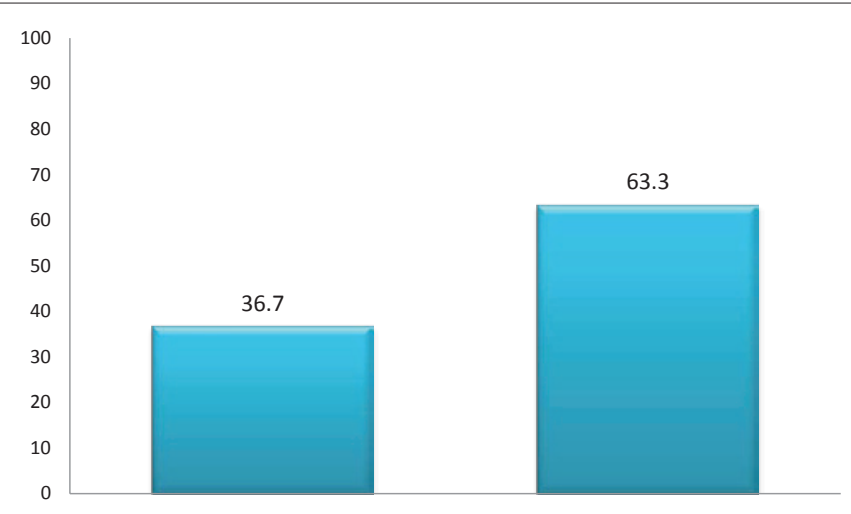

Perceived to be at High Risk Perceived to be at Low Risk

Figure 2: Percentage distribution of perceived risk of HIV infection among MSM in Dar Es Salaam, Mainland Tanzania.

\section{Association between HIV risk perception and socio- demographic and sexual practices}

Table 3 presents the results of a regression analysis of the independent association between perceived risk of HIV and other variables. Younger same sex practicing men were almost two times more likely to have low perceived risk for HIV infection than the older group [AOR, 1.7, 95\%CI: 1.0-6.5)]. Furthermore, men with low perceived risk for HIV infection were considerably more likely to have had more than one partner in the past month [AOR 4.3, 95\% CI: 1.111.2] and also more likely to engage in both opposite-sex and same-sex relationships [AOR, 3.6(95\%CI: 1.0-15.0). Lower risk perception was also associated with a relatively lower likelihood that a condom had been used during the last sexual encounter [AOR, 0.3(95\%CI: 0.2-0.7)] and that the person had ever been tested for HIV [AOR 0.3, 95\% CI: 0.1-0.9]. Additionally, low perceived risk was associated with a 6 times higher likelihood that alcohol had been used during the last sexual encounter [AOR, 6.0(95\%CI: 2.3-16.9)] (Table 3).

\section{Discussion}

The literature that specifically deals with contemporary male samesex practices is still limited in mainland Tanzania, and this is the first epidemiological study that has ever been carried out among same-sex practicing men in the country. While it is a study of limited size, it offers important insights into sexual practices, condom use, HIV testing, and self-perceived risk for HIV among men who have sex with men in
Dar es Salaam, and contributes to the scarce literature regarding this population in Africa. In other parts of the world, anal sex between men and men or between men and women has been documented for many years, but in Sub-Saharan Africa, research on this area has been long neglected due to stigma or the belief that this practice did not exist.

MSM in this study were mainly younger men with an age at first sexual experience of about 12 years. These findings are similar to what has been reported in other studies in which age at sexual debut ranged from 12-15 years [8,10]. Data from Brazil revealed that one quarter of study participants in Metropolitan City were found to have had experienced sexual debut before the age of 13 years with partners 4 years older than them [21-23]. This indicates that sexual abuse is closely associated with sexual orientation. Young people who are involved in sexual abuse have been reported to have higher risk score for STIs including HIV infection. A substantial proportion of MSM indicated their first anal sex to have occurred in school mostly as a form of sexual abuse and this has been reported elsewhere [24-25]. This highlights the importance of targeting schools as an intervention arena to prevent abuse and promote safer sexual behaviors.

A large majority of men in this population practiced unprotected first anal sex, indicating a high probability of STI transmission given the fact that first anal sex is associated with bruising and trauma. Studies in Senegal and elsewhere in Africa corroborate this assumption and have shown the highest risk of HIV infection among MSM practicing anal sex [26-28]: Prevalence of HIV infection has been shown to range from $12.3 \%$ in Zanzibar to $33 \%$ in Zambia [1-2,4,29-30]. The finding that $36.7 \%$ of the surveyed men reported having used a condom the last time they had sex is of some significance in the context of transmission of STIs including HIV. Although this was a considerably higher percentage than the overall proportion of Tanzanian men who reported condom use during their last sexual encounter in 2004 (20.8\%), it is nonetheless lower than the overall proportion of Tanzanian men who reported having used a condom the last time they had sex with a non-marital, non-cohabiting partner that same year (51.1\%) [16]. While some MSM may apply strategies other than condom use to protect themselves and their partners from HIV (such as 'negotiated safety' described in Australia and elsewhere), it is likely that a higher frequency of condom use would offer added protection against HIV in the population under consideration, especially if condoms are used concomitantly with water-based lubricants.

There is some evidence that multiple sexual partnerships are

\begin{tabular}{|c|c|c|}
\hline Reference: Low perceived risk & a Model I OR(95\% Cl) & $\beta$ Model II AOR(95\% Cl) \\
\hline Age ( $\leq 24$ years $)$ & $2.9(1.3-6.1)$ & $1.7(1.0-6.5)$ \\
\hline Age at first sex ( $\leq 12$ years) & $1.1(0.6-7.8)$ & $0.9(0.4-9.2)$ \\
\hline No. sexual partner last months $(\geq 2)$ & $4.5(1.2-10.6)$ & $4.3(1.1-11.2)$ \\
\hline Have female partners (Yes) & $3.5(1.1-13.1)$ & $3.6(1.0-15.0)$ \\
\hline No. of Female partners $(\geq 2)$ & $1.0(0.3-17.0)$ & $0.8(0.2-17.5)$ \\
\hline Condom use last sex(Yes) & $0.2(0.1-0.8)$ & $0.3(0.2-0.7)$ \\
\hline Ever used alcohol (Yes) & $1.1(0.5-2.3)$ & $1.0(0.5-2.5)$ \\
\hline Use alcohol during last sex(Yes) & $6.1(2.4-17.6)$ & $6.0(2.3-16.9)$ \\
\hline Ever used drugs (Yes) & $2.1(0.9-12.4)$ & $1.9(0.7-14.5)$ \\
\hline Used drugs during last sex (Yes) & $3.6(1.0-19.1)$ & $3.0(0.8-21.1)$ \\
\hline Had HIV test (Yes) & $0.4(0.1-0.8)$ & $0.3(0.1-0.9)$ \\
\hline Time since HIV test ( $\geq 4$ years ago) & $0.9(0.2-1.1)$ & $0.9(0.1-1.7)$ \\
\hline
\end{tabular}

$\alpha$ - Reduced (unadjusted) model, $\beta$-Full (adjusted) model; $\mathrm{Cl}-95 \%$ Confidence Intervals, OR-Odds Ratio; AOR-Adjusted Odds Ratio (Adjusted for all other variables)

Table 3: Perceived risk for HIV infection and practice of risk behaviors among MSM in Dar Es Salaam, Mainland Tanzania. 
very common among MSM [2,13,21,31-32]. Since multiple sexual relationships increase the opportunity for exposure to sexually transmissible pathogens such as HIV, this puts this group at higher risk of infection. In this study, the mean number of life time sexual partners was found to be 35 with $94 \%$ of the participants reporting more than 2 sexual partners in the 3 months preceding the survey. However, lifetime number of sexual partners reported in this study was relatively low compared with studies done in the USA and Latin America [3,33].

MSM sexual networks have been reported to be closely linked to predominantly heterosexual networks in the general population in Africa and elsewhere $[2,14,26]$. While all of the men included in the study engaged sexually with other men either occasionally or regularly, close to one-third $(32.6 \%)$ of them also engaged in sexual and/ or marital relationships with women. Involvement of African MSM in simultaneous same sex and heterosexual relationships could result from stigma attached to this practice influencing them to adopt the socially acceptable heterosexual lifestyle in the eyes of the community, both to avoid public disclosure and also to help dispel doubts about their masculinity [5-7,22,34]. Moreover, anal sex is considered a crime in Tanzania as in many African countries and is considered an abomination by both the Islamic and Christian religions to which most of our participants belong. These factors contribute to the clandestine nature of this behavior and make public disclosure difficult. This suggests that since Dar Es Salaam's MSM population includes many people who are in heterosexual marriages and not identifying themselves as MSM, intervention development should take into account the close links between MSM risk of HIV transmission and acquisition and that of negela population sexual networks [1,14-15].

Perceived risk for HV infection was found to be low in this population. As expected - and in line with findings reported in other studies - a low perceived vulnerability to HIV infection was associated with a higher number of sexual partnerships and lower likelihood for condom use and HIV testing [1,29,35-43]. Some MSM even believed that anal sex carries a lower risk of infection. Similar findings were also reported in Zambia, where $80 \%$ of same-sex practicing men did not know whether condoms need to be used during anal sex and more than half believed that anal sex is safer than vaginal sex [10]. A study in Mombasa, Kenya revealed similar results among MSM and reported a preference for "skin-to skin" sexual contact to be common [32].

Risk perception is key to the development of health attitudes and behaviors that may lead to reduced infection risk and susceptibility. The reported low perceived risk of HIV infection in this population subgroup may be due to the lack of appropriate messages on the potential for such infections from anal sex practices and the need for use of condoms and lubrication, and consequently underpins the gap in prevention characterized by the lack of programmes specifically targeting MSM and their vulnerabilities.

As has been shown elsewhere, if the goal is to prevent new HIV infections, the most effective and sustainable strategies often arise when those at risk and those who have specialized knowledge about HIV collaborate and develop mutual insight into each other's perspectives and experiences. It has at times been argued that such joint exploration may be difficult to accomplish with MSM in African contexts based on the common beliefs that MSM practices do not occur and that if they do, they are practiced by individuals who are hard to reach [20]. However, it took only two weeks to recruit the 150 men who participated in this survey.

The findings reported in this study could be affected by a number of limitations. The use of RDS may have violated the statistical assumption of independent observation and affected the efficiency of the study. However, weighting of the data may have, to some extent, alleviated this problem $[17,19]$. Desirability bias could affect sensitive sexual behavioral data in various directions. As this was an African study, for instance, underreporting such as that of lifetime number of sexual partners could have occurred. Finally, the cross sectional nature of this study limits our ability to make conclusions about causal relationships. However, most of the statistical relationships found are supported by data from other studies with stronger designs.

\section{Conclusions}

Practice of anal sex among men occurs in Tanzania with younger men forming the majority of the group. Perceptions of the potential for HIV infection due to unprotected anal sex among MSM in Dar Es Salaam, Tanzania appear to be fairly low. Only a third of the participants were found to have high perceived risk of HIV infection. MSM sexual networks were closely linked to those of heterosexual general population networks with substantial proportion of men married to women or having female sexual partners.

While more research among MSM in Dar Es Salaam is needed to accurately estimate the magnitude of STI and HIV infection and confer an in-depth understanding of behavioural, social and environmental determinants to be targeted in prevention programs, this study points to several topics that can be further explored as part of HIV-related prevention programming among such men. The ease with which participants in this study were recruited is likely to mean that MSM will also be willing to take part in collaborative HIV prevention efforts if they are invited to participate.

\section{Acknowledgements}

We wish to extend our gratitude to all study participants for their time and active participation. The writing of this manuscript was made possible by the Harvard Global Health Initiative through its Global Health Scholar program.

\section{References}

1. Smith AD, Tapsoba P, Peshu N, Sanders EJ, Jaffe HW (2009) Men who have sex with men and HIVIAIDS in Sub-Saharan Africa. Lancet 374: 416-422.

2. Baral S, Burrell E, Scheibe A, Brown B, Beyrer C, et al. (2011) HIV risk and associations of HIV infection among men who have sex with men in peri-urban Cape Town, South Africa. BMC Public Health 11: 766.

3. Centre for Diseases Control and Presearvation. (2009) HIVIAIDS and men who have sex with men. Atlanta, Georgia:

4. Dahoma M, Johnson L, Holman A, Millar LA, Mussa M, et al. (2011) HIV and related risk behavior among men who have sex with men in Zanzibar, Tanzania: results of a behavioral surveillance survey. AIDS Behav 15: 186-192.

5. Fay H, Baral SD, Trapence G, Motimedi F, Umar E, et al. (2011) Stigma, health care access, and HIV knowledge among men who have sex with men in Malawi, Namibia, and Botswana. AIDS Behav 15: 1088-1097.

6. MCKirnan DJ (1998) On the Margins- Men who have sex with men and HIV in the developing world. Int J Public Health 9: 494-499.

7. Niang C TP, Weisse E (2003) Its raining stones Stigma violence and HIV vulnerability among men who have sex with men in Dakar Senegal. Cult Health Sex 5: 499-512.

8. Kajubi P, Kamya MR, Raymond HF, Chen S, Rutherford GW, et al. (2008) Gay and bisexual men in Kampala, Uganda. AIDS Behav 12: 492-504.

9. Rispel LC, Metcalf CA, Cloete A, Moorman J, Reddy V (2011) You become afraid to tell them that you are gay: health service utilization by men who have sex with men in South African cities. J Public Health Policy 32: S137-S151.

10. Zulu W (2009) Men who have sex men (MSM)-a sidelined population in HIVIAIDS prevention Programs in Zambia. 5th IASA Conference on HIV 
Citation: Mmbaga EJ, Dodo MJ, Leyna GH, Moen K, Leshabari MT (2012) Sexual Practices and Perceived Susceptibility to HIV Infection among Men who have Sex with Men in Dar Es Salaam, Mainland Tanzania. J AIDS Clinic Res S1:012. doi:10.4172/2155-6113.S1-012

Patogenesis, Treatment and prevention, International AIDS Society, Lusaka Zambia.

11. Li X, Lu H, Ma X, Sun Y, He X, et al. (2012) HIVIAIDS-Related Stigmatizing and Discriminatory Attitudes and Recent HIV Testing Among Men Who Have Sex With Men in Beijing. AIDS Behav 16: 499-507.

12. Merrigan M, Azeez A, Afolabi B, Chabikuli ON, Onyekwena O, et al. (2011) HIV prevalence and risk behaviours among men having sex with men in Nigeria. Sex Transm Infect 87: 65-70.

13. Price MA, Rida W, Mwangome M, Mutua G, Middelkoop K, et al. (2012) Identifying at-risk populations in Kenya and South Africa: HIV incidence in cohorts of men who report sex with men, sex workers, and youth. J Acquir Immune Defic Syndr 59: 185-193.

14. Morris M, Podhisita C, Wawer MJ, Handcock MS (1996) Bridge population in spread of HIV IAIDS in Thailand. AIDS 11: 1265-1271.

15. Johnston LG, Holman A, Dahoma M, Miller LA, Kim E, et al. (2010) HIV risk and the overlap of injecting drug use and high-risk sexual behaviours among men who have sex with men in Zanzibar (Unguja), Tanzania. Int J Drug Policy 21: 485-492.

16. National Bureau of Statistics OM (2007-2008) Tanzania HIVIAIDS and Malaria Indicator Survey. Calverton Maryland: TACAIDS.

17. Mantecón A, Juan M, Calafat A, Becoña E, Román E (2008) RespondentsDriven Sampling: A new sampling method to study visible and hidden populations. Adicciones 20: 161-169.

18. Wejnert C (2009) AN EMPIRICAL TEST OF RESPONDENT-DRIVEN SAMPLING: POINT ESTIMATES, VARIANCE, DEGREE MEASURES, AND OUT-OF-EQUILIBRIUM DATA. Sociol Methodol 39: 73-116.

19. Carballo-Diéguez A, Balan I, Marone R, Pando MA, Dolezal C, et al. (2011) Use of Respondent Driven Sampling (RDS) Generates Very Diverse Sample of Men Who Have Sex with Men (MSM) in Buenos Aires, Argentina. PLoS One 6: e27447.

20. Moen K, Aggleton P, Leshabari MT, Middelthon AL (2012) Not at all so hard-toreach: same-sex attracted men in Dar es Salaam. Cult Health Sex 14: 195-208.

21. Tabet SR, de Moya EA, Holmes KK, Krone MR, de Quinones MR, et al. (1996) Sexual behaviors and risk factors for HIV infection among men who have sex with men in the Dominican Republic. AIDS 10: 201-206.

22. Gaelle B, Allen C (2008) Social cultural factors driving the HIV epidemic in the Caribbean. Caribbean Health Research Council .

23. Lugalla JLP (1995) Crisis of Urbanization and poverty in Tanzania: A study on urban poverty and survival politics. J Urban Dev 12: 432-436

24. Friedman MS, Marshal MP, Guadamuz TE, Wei C, Wong CF, et al. (2011) A meta-analysis of disparities in childhood sexual abuse, parental physical abuse, and peer victimization among sexual minority and sexual nonminority individuals. Am J Public Health 101: 1481-1494.

25. Saewyc E, Skay C, Richens K, Reis E, Poon C, et al. (2006) Sexual orientation, sexual abuse, and HIV-risk behaviors among adolescents in the Pacific Northwest. Am J Public Health 96: 1104-1110.

26. Ndiaye P, Fall A, Tal-Dia A, Faye A, Diongue M (2011) Knowledge, attitudes and practices related to STD and HIVIAIDS: men having sex with men in Senegal. Rev Epidemiol Sante Publique 59: 305-311.

27. Cheikh K (2011) Meeting the sexual needs of men who have sex with men in Senegal. Horizon programme.

28. Geibel S, Tun W, Tapsoba P, Kellerman S (2010) HIV vulnerability of men who have sex with men in developing countries: Horizons studies, 2001-2008. Public Health Rep 125: 316-324.

29. Baral S (2008) A systematic review of HIV epidemiology and risk factor among men who have sex with men in Sub Saharan -Africa 2000-2008. xvil international AIDS Conference, Mexico City.
30. Baral S, Trapence G, Motimedi F, Umar E, lipinge S, et al. (2009) HIV prevalence, risks for HIV infection, and human rights among men who have sex with men (MSM) in Malawi, Namibia Botswana. PLoS One 4: e4997

31. Chapman J, Koleros A, Delmont Y, Pegurri E, Gahire R, et al. (2011) High HIV risk behavior among men who have sex with men in Kigali, Rwanda: making the case for supportive prevention policy. AIDS Care 23: 449-455.

32. Sanders EJ, Graham SM, Okuku HS, van der Elst EM, Muhaari A, et al. (2007) HIV-I Infection in high risk men who have sex with men In Mombasa Kenya. AIDS 21: 2513-2520.

33. Centers for Disease Control and Prevention (CDC) (2008) Trends in HIV IAIDS diagnoses among men who have sex with men--33 states, 2001-2006. MMWR Morb Mortal Wkly Rep 57: 681-686.

34. Boyce P (2001) Rapid Ethnographic Assessment of male-male sexuality and sexual health in Kathmandu Nepal. Family Health International.

35. McKirnan DJ, Peterson PL (1989) Alcohol and drug use among homosexua men and women: Epidemiology and population characteristics. Addict Behav 14: $545-553$.

36. Mmbaga EJ, Hussain A, Leyna GH, Mnyika KS, Sam NE, et al. (2007) Prevalence and risk factors for HIV-1 infection in rural Kilimanjaro region of Tanzania: implications for prevention and treatment. BMC Public Health 7: 58.

37. Rusch M, Lampinen TM, Schilder A, Hogg RS (2004) Unprotected ana intercourse association with recreational drug use among young MSM depends on partner type and intercourse role. Sex Transm Dis 31: 492-498.

38. Ghebremichael M, Paintsil E, Larsen U (2009) Alcohol Abuse, Sexual Risk Behaviors, and Sexually Transmitted infection in Moshi urban District, Northern Tanzania. Sex Trans Dis 36: 102-107.

39. Aggleton P (1999) Men who have sex with men in London. Sex Trans Dis 26 :463-471.

40. MCKirnan DJ, Peterson PL (1989) Psychosocial and cultural factors in alcoho and drug abuse: an analysis of a homosexual community. Addict Behav 14: 555-563.

41. Scott-Sheldon LA, Carey MP, Carey KB, Cain D, Harel O, et al. (2012) Patterns of alcohol use and sexual behaviors among current drinkers in Cape Town South Africa. Addict Behav 37: 492-497.

42. Kalichman SC Cain D, Simbayi LC (2011) Multiple recent sexual partnerships and alcohol use among sexually transmitted infection clinic patients, Cape Town, South Africa. Sex Trans Dis 38: 18-23.

43. Kalichman SC, Simbayi L, Jooste S, Vermaak R, Cain D (2008) Sensation seeking and alcohol use predict HIV transmission risks: prospective study of sexually transmitted infection clinic patients, Cape Town, South Africa. Addict Behav 33: 1630-1633. 